\title{
EL DERECHO A LA SALUD DE LOS EXTRANJEROS RESIDENTES EN SITUACIÓN IRREGULAR: SOBRE LA LEGITIMIDAD CONSTITUCIONAL DEL RD-LEY I6/2012
}

\author{
Nuria SANGÜESA RUIZ* \\ Profesora DE DERECHO CONSTITUCIONAL \\ UNIVERSIDAD DE LA RIOJA
}

SUMARIO: I. Introducción. II. Denegación de la condición de asegurado a los extranjeros en situación irregular. III. Panorama autonómico. IV. Algunas preguntas sobre la adecuación constitucional de la medida. V. Los recursos de inconstitucionalidad pendientes ante el TC. Perspectivas abiertas por los AATC 239/20I2 y II4/20I4. VI. Conclusión.

RESUMEN: El trabajo analiza la corrección constitucional de la norma que niega a los extranjeros residentes irregulares el derecho a la asistencia sanitaria normalizada con cargo a fondos públicos (RD-ley I6/20I2). Para ello tiene en cuenta el vínculo entre el derecho a la salud (art. $43 \mathrm{CE}$ ) y los derechos fundamentales a la vida y la integridad física (art. I5 CE), y su transformación asociada a la doctrina jurisprudencial sobre derechos de los extranjeros, el juego del principio de igualdad, las técnicas de razonabilidad y proporcionalidad y las normas internacionales de derechos humanos. Se analizan también la desigual gama de respuestas de las Comunidades Autónomas a la situación provocada por la norma, y los AATC 239/20I2 y II4/20I4.

PalabraS Clave: Asistencia sanitaria. Extranjeros. Inmigrantes irregulares. Derecho a la salud. Derecho a la vida. Integridad física. Igualdad.

ABSTRACT: This essay analyses the constitutionality of the Spanish regulation that denies the access to regular public health care to illegal aliens (Real Decreto-ley 16/2012). For this, we consider the bond between the right to health (article 43 of the Spanish Constitution) and rights to life and physical integrity (article I5 of the Spanish Constitution). This link has changed because of the constitutional jurisprudence about alien's rights, the equality principle and the tests of reasonableness and proportionality, and international human rights law. We also consider the different answers to the measure of Comunidades Autónomas and the resolutions of the Constitutional Court of Spain (Auto del Tribunal Constitucional 239/2012 and Auto del Tribunal Constitucional II4/20I4).

KeY wORDS: Access to healthcare. Aliens. Irregular aliens. Right to health. Right to life. Physical integrity. Equality. Discrimination.

\footnotetext{
* Beneficiaria de la ayuda pre-doctoral BES-2012-056r48, en el marco del Proyecto de Investigación DER 20II-23566 (Ministerio de Economía y Competitividad).
} 


\section{Introducción}

En abril de 2012 se aprobó el Real Decreto-ley 16/2012, de 20 de abril, de medidas urgentes para garantizar la sostenibilidad del Sistema Nacional de Salud y mejorar la calidad $y$ seguridad de sus prestaciones (RD-ley I6/2012), que supuso una importante reforma del Sistema Nacional de Salud (SNS). Esta comunicación contiene un análisis desde el Derecho constitucional de una de las medidas incorporadas en dicho decreto-ley: la exclusión de los extranjeros en situación irregular del acceso a la asistencia sanitaria normalizada con cargo a fondos públicos.

La situación plantea tres problemas de orden jurídico-constitucional.

I. Un problema competencial, en el que resulta fundamental la delimitación de las competencias estatales y autonómicas en materia de asistencia sanitaria.

2. Un problema del sistema de fuentes: rango de Real Decreto-ley, a la vista de los límites materiales impuestos por la Constitución.

3. Capacidad constitucional del legislador en la definición del ámbito subjetivo del derecho de acceso a la asistencia sanitaria, así como en la regulación de dicho acceso.

Estos problemas se han planteado ante el TC en procesos diferentes, sobre los que deberá emitir distintas resoluciones.

En esta comunicación dedicaremos especial atención al tercero de los problemas enumerados: cómo se configuran derecho y acceso cuando los sujetos son extranjeros.

\section{Denegación de la condición de asegurado a los extranjeros en situación irregular}

Con anterioridad a la aprobación del RD-ley I6/2012, todos los extranjeros empadronados en España, con independencia de su situación administrativa, gozaban del derecho a la asistencia sanitaria «en las mismas condiciones que los españoles», de acuerdo con el art. I2.I de la Ley Orgánica 4/2000, de 11 de enero, sobre derechos y libertades de los extranjeros en España y su integración social (LOEx).

El RD-ley I6/20I2 modifica varias previsiones legales con el resultado de denegar a los extranjeros residentes en situación irregular el acceso a la asistencia sanitaria normalizada con cargo a fondos públicos. ${ }^{\mathrm{I}}$

La norma introduce en la regulación del Sistema Nacional de Salud (SNS) la figura del «asegurado», de manera que la asistencia sanitaria en España con cargo a fondos públicos se garantizará a las personas que ostenten tal condición (art. 3 de la Ley 16/2003, de 28 de mayo, de cohesión y calidad del Sistema Nacional de Salud, según queda redactada por el RD-ley I6/20I2). Los extranjeros en situación irregular no pueden acceder a la situación de asegurado, según la subsiguiente regulación sobre los modos de acceso a tal condición.

Se exceptuaron un grupo de situaciones especiales en que los extranjeros «no registrados ni autorizados como residentes en España» podrían acceder a «determinadas

\footnotetext{
${ }^{1}$ Modificación del art. 3 de la Ley 16/ 2003, de 28 de mayo, de cohesión y calidad del Sistema Nacional de Salud (art. 1 del RD-ley 16/2012). Modificación del art. 12 de la LOEx (Disposición Final tercera RD-ley 16/2012).
} 
modalidades» de asistencia sanitaria: asistencia al embarazo, parto y posparto; urgencia por enfermedad grave o accidentes. Además, todos los extranjeros menores de I8 años recibirían asistencia sanitaria en las mismas condiciones que los españoles (art. 3ter de la Ley I6/2003, según queda redactada por el RD-ley I6/20I2).

El Real Decreto 1192/2012, de 3 de agosto, por el que se regula la condición de asegurado $y$ de beneficiario a efectos de la asistencia sanitaria en España, con cargo a fondos públicos, a través del Sistema Nacional de Salud (RD II92/20I2) desarrolló reglamentariamente estas previsiones.

A partir de la aprobación de estas normas, para los extranjeros no nacionales de países de la UE, el Espacio Económico Europeo, o Suiza, es necesario contar con autorización de residencia y/o trabajo para acceder a la asistencia sanitaria normalizada del SNS con cargo a fondos públicos.

En cuanto a las personas de nacionalidad de algún Estado Miembro de la Unión Europea, del Espacio Económico Europeo o de Suiza deben, si no se encuentran en alguno de los supuestos relacionados con la afiliación a la Seguridad Social establecidos en el punto 2 del art. 3 de la Ley 16/2003, «estar inscritos en el Registro Central de Extranjeros» (art. 2.I.b)4ffl RD II92/20I2).

Los preámbulos del RD-ley I6/20I2 y del RD II92/20I2 justifican la aprobación de las reformas basándose en argumentos relacionados con la sostenibilidad de la sanidad pública en España y con la eficiencia del SNS. El punto III del preámbulo del RD-ley I6/20I2 se refiere específicamente a la regulación de la condición de asegurado.

La nueva regulación de la condición de asegurado, que priva de dicha condición a los extranjeros en situación irregular, se justifica en una serie de situaciones que tienen que ver, básicamente, con la asistencia sanitaria a ciudadanos de Estados Miembros de la UE y otros Estados parte en el Acuerdo sobre el Espacio Económico Europeo. Ello se deduce de las referencias normativas que se realizan, ${ }^{2}$ de la remisión a un dictamen motivado de la Comisión Europea acerca de la emisión de tarjeta sanitaria europea,3 y del contenido del informe del Tribunal de Cuentas en el que se justifican las medidas. 4

\footnotetext{
2 El punto III del preámbulo del RD-ley 16/2012 se hace referencia al Reglamento (CE) no 883/2004 del Parlamento Europeo y del Consejo, de 29 de abril de 2004, sobre la coordinación de los sistemas de seguridad social, y a su reglamento de aplicación, el Reglamento (CE) n ${ }^{\circ}$ 987/2009 del Parlamento Europeo y del Consejo, de 16 de septiembre de 2009, por el que se adoptan las normas de aplicación. Asimismo, el preámbulo se refiere a la falta de transposición literal del art. 7 de la Directiva 2004/38/CE, del Parlamento Europeo y del Consejo, de 29 de abril de 2004, relativa al derecho de los ciudadanos de la Unión y de los miembros de sus familias a circular y residir libremente en el territorio de los Estados miembros.

${ }^{3}$ Dictamen motivado de la Comisión Europea 2009/2341 dirigido al Reino de España por su negativa a expedir la tarjeta sanitaria europea a personas residentes en España con derecho a recibir asistencia sanitaria con arreglo a la normativa de algunas comunidades autónomas.

${ }^{4}$ Aunque en el preámbulo del RD-ley 16/2012 no se especifica la referencia exacta del informe del Tribunal de Cuentas a que se remite, se trata del Informe de fiscalización de la Gestión de las Prestaciones de Asistencia Sanitaria derivadas de la aplicación de los Reglamentos Comunitarios y Convenios Internacionales de la Seguridad Social aprobado por el pleno del Tribunal de Cuentas el 29 de marzo de 2012 (Resolución de 18 de diciembre de 2012, aprobada por la Comisión Mixta para las Relaciones con el Tribunal de Cuentas en relación con el Informe de fiscalización de la Gestión de las Prestaciones de Asistencia Sanitaria derivadas de la aplicación de los Reglamentos Comunitarios y Convenios Internacionales de la Seguridad Social, publicada en el BOE núm. 72, lunes 25 de marzo de 2013, sec. III, pág. 23154).
} 
De una lectura conjunta de las referencias contenidas en la justificación de las normas, así como de posteriores declaraciones, en diferentes sedes, por parte de distintos representantes del Gobierno, parece deducirse que uno de los principales problemas que se quieren resolver tiene que ver con situaciones creadas por el derecho de la UE. Se intentaría evitar que determinados ciudadanos comunitarios accedieran a la condición de asegurados, lo que de acuerdo con la normativa europea les otorgaría derechos como el acceso a la tarjeta sanitaria europea o el derecho al reembolso de las prestaciones de asistencia sanitaria disfrutadas en otros estados de la UE. Tal objetivo se alcanzaría mediante la denegación de la condición de asegurado a cualquier persona no autorizada a residir en España (caso de nacionales de terceros Estados) o registrada como residente (caso de ciudadanos de Estados Miembro de la UE y otros Estados parte en el Acuerdo sobre el Espacio Económico Europeo). Así, la situación en que quedan los nacionales de terceros Estados afectados por la medida aparece como una especie de «efecto colateral» de la misma, que poco tiene que ver con sus objetivos declarados, si atendemos a las justificaciones proporcionadas por los responsables de su puesta en marcha.5

Esta impresión, presente desde la aprobación de las normas referidas, parece confirmarse a la luz de la evolución de los acontecimientos.

La medida fue, ya antes de su aprobación, objeto de críticas provenientes de distintos sectores. 6

La aplicación del Real Decreto-ley por parte de las Comunidades Autónomas ha sido muy dispar, cuestión sobre la que volveremos más adelante. Algunas han elaborado normas proporcionando acceso a la asistencia sanitaria a personas excluidas de la condición de asegurado a nivel estatal. Otras han llevado a cabo actuaciones a nivel administrativo con el objeto de proporcionar, a todas o algunas de estas personas, atención sanitaria no incluida en el Real Decreto-ley.

El RD-ley I6/20I2 ha sido objeto de diversos recursos de inconstitucionalidad. Y varios de ellos impugnan el precepto que conlleva la retirada del derecho de acceso a la asistencia sanitaria normalizada a los extranjeros en situación irregular.7

Las críticas, por otra parte, no se han limitado a la regulación establecida, sino también a su aplicación por las diferentes administraciones españolas.

\footnotetext{
${ }^{5}$ Declaraciones de la entonces Ministra de Sanidad, Servicios Sociales e Igualdad en el debate de convalidación en el Congreso de los Diputados del RD-ley 16/2012. DS. Congreso de los Diputados, Pleno y Dip. Perm., núm. 31, de 17/05/2012, págs. 57-58, 62-63. Alegaciones del Abogado del Estado recogidas en punto 7 de los antecedentes del ATC 114/2014 (especialmente, punto b) de los mismos). Declaraciones del Secretario general de sanidad y consumo en comparecencia ante la Comisión de Sanidad y Servicios Sociales. DS. Congreso de los Diputados, Comisiones, núm. 888 , de 20/08/2015, págs. 54-56.

${ }^{6}$ En el contexto de los llamados movimientos sociales, surgieron iniciativas ciudadanas de acompañamiento a personas afectadas por la medida e incluso de «objeción de conciencia» del personal sanitario y administrativo de los servicios sanitarios del SNS http://yosisanidaduniversal.net/portada.php (último acceso a 05-10-2015).

${ }^{7}$ Recursos de inconstitucionalidad interpuestos por el Parlamento de Navarra (recurso de inconstitucionalidad núm. 4123-2012; $\mathrm{BOE} \mathrm{n}^{\circ}$ 176, de 24 de julio de 2012), por el Gobierno de la Junta de Andalucía (recurso de inconstitucionalidad núm. 4285-2012; BOE 228, de 21 de septiembre de 2012), por el Gobierno de Cataluña (recurso de inconstitucionalidad núm. 414-2013; BOE 46, de 22 de febrero de 2013), por el Gobierno Vasco (recurso de inconstitucionalidad núm. 419-2013; BOE 46, de 22 de febrero de 2013), por el Gobierno de Canarias (recurso de inconstitucionalidad núm. 433-2013; BOE 46, de 22 de febrero de 2013).
} 
Los argumentos en que se ha basado la oposición al Real Decreto-ley han sido de muy diversa índole, y pueden clasificarse en diferentes grupos, aunque en los distintos discursos suelen encontrarse entremezclados e interrelacionados. Encontramos argumentos relacionados con la legalidad internacional: legitimidad de la medida desde el punto de vista de los instrumentos internacionales de derechos humanos. En otros casos se fundamenta el rechazo de la medida en su supuesta inconstitucionalidad: bien desde el punto de vista competencial, bien desde el recurso a la legislación de urgencia, e incluso desde su ajuste al sistema constitucional de derechos fundamentales y principios rectores.

En fin, ha recibido críticas contundentes sobre su efectividad y capacidad para cumplir los objetivos pretendidos.

En esta línea se ha advertido de su ineficiencia económica: diversos estudios consideran que prestar servicios sólo de urgencia a las personas inmigrantes sin permiso de residencia resulta más costoso, a largo plazo, que proporcionar una atención primaria universal. ${ }^{8}$ Cabe destacar a este respecto que el propio TC se ha hecho eco de este aspecto (AATC 239/20I2/5 y II4/20I4/6).

\section{Panorama autonómico}

Veamos ahora la gama de respuestas autonómicas a la situación provocada a la entrada en vigor del RD-ley i6/2012.

La respuesta ha sido muy desigual, según hemos anticipado.9

Algunas CCAA (Madrid, Castilla-La Mancha, Cantabria, La Rioja, Islas Baleares, Extremadura, Aragón o Murcia) aplicaron plenamente el RD-ley I6/2012, denegando el acceso a la atención sanitaria normalizada a los extranjeros en situación irregular.

Otras CCAA, desarrollaron diferentes mecanismos y procedimientos que permitieron una aplicación «matizada» del RD-ley I6/2012, que varían mucho de unas Comunidades a otras (Castilla-León, Valencia, Galicia, Canarias).

Otras CCAA elaboraron normativas autonómicas reconociendo a los extranjeros en situación irregular el acceso a sus sistemas de salud en las mismas condiciones que a sus ciudadanos. La mayoría de estas previsiones son instrucciones internas (caso de Andalucía, Asturias y Cataluña). En otros casos, se elaboraron decretos (caso del País Vasco, con el Decreto II4/20I2, de 26 de junio, sobre régimen de las prestaciones sanitarias del Sistema

\footnotetext{
${ }^{8}$ Recientemente, la Agencia Europea de los Derechos Fundamentales ha publicado un informe en este sentido, FRA European Union Agency for Fundamental Rights, Cost of exclusión from healthcare. The case of migrants in an irregular situation, Oficina de Publicaciones de la Unión Europea, Luxemburgo, 2015, disponible en http://fra.europa.eu/en/publication/2015/cost-exclusion-healthcare-case-migrants-irregular-situation (último acceso 05-10-2015).

En la misma línea la Red de Denuncia y Resistencia al RDL 16/2012 (REDER), Informe: Radiografia de la reforma sanitaria. La universalidad de la exclusión, septiembre de 2015, págs. 14-15, en el que se citan informes al respecto. Disponible en http://www.medicosdelmundo.org/index.php/mod.documentos/mem.descargar/fichero.documentos_INF_REDER_v4 _\%282\%29-min_b5ea042b\%232E\%23pdf (último acceso a 5 de octubre de 2015).

${ }^{9}$ Delgado Del Rincón, «El derecho a la asistencia sanitaria de los inmigrantes irregulares: reflexiones sobre la reforma introducida por el Real Decreto-ley 16/2012, de 20 de abril», REDP, núm 163, 2014, págs. 220 y ss. Analiza las diversas respuestas autonómicas frente a la medida, clasificándolas en tres grupos en función del grado de aplicación de la normativa estatal.
} 
Nacional de Salud en el ámbito de la Comunidad Autónoma de Euskadi) o incluso leyes autonómicas (caso de Navarra, con la Ley Foral 8/2013, de 25 de febrero, por la que se reconoce a las personas residentes en Navarra el derecho de acceso a la asistencia sanitaria gratuita del sistema público sanitario de Navarra).

Este mapa ha ido variando a lo largo del tiempo de vigencia del RD-ley I6/20I2. En muchas ocasiones, las CCAA no han impartido instrucciones claras acerca del funcionamiento de los servicios sanitarios autonómicos a este respecto. Las normativas internas, en ocasiones, resultan oscuras. Asimismo, ha habido diferentes etapas y cambios normativos a lo largo de la vigencia del RD-ley.

Por otra parte, diversas organizaciones sociales y actores institucionales (como el Defensor del Pueblo) han denunciado vulneraciones del propio RD-ley, identificando casos en que se ha denegado el acceso a extranjeros en vulneración de dicha norma, y lamentando la inseguridad jurídica producida por la dispersión normativa y la desorganización administrativa. ${ }^{\text {IO }}$

Las normas vasca y navarra aludidas supra (Decreto II4/20I2, en el País Vasco; y Ley Foral 8/20I3) fueron objeto de sendos recursos de inconstitucionalidad, presentados por el Gobierno de la Nación. Dichas normas, cada una en su territorio, extienden el ámbito subjetivo del derecho a la asistencia sanitaria normalizada para ampliarla a los extranjeros en situación irregular. Los recursos de inconstitucionalidad, que aún no se han resuelto, se fundan en la violación del sistema constitucional de competencias.

En ambos casos, el Gobierno invocó los arts. I6r.2 CE y 30 LOTC con el objeto de suspender la vigencia de la norma autonómica. Y también en ambos casos, el TC se ha visto obligado a pronunciarse acerca del mantenimiento o levantamiento de la suspensión. En los dos casos el TC ha dictado Auto levantando la suspensión en lo relativo al acceso de los extranjeros irregulares a la asistencia sanitaria (AATC 239/20I2, de I2 de diciembre, relativo al caso vasco; y II4/20I4, de 8 de abril, acerca del supuesto navarro). Más adelante en este mismo trabajo examinamos las argumentaciones contenidas en dichas resoluciones jurisprudenciales.

A partir de marzo de 2015, y sobre todo tras las elecciones municipales y autonómicas celebradas en mayo de 2015, la situación ha dado un importante giro.

En marzo de 20I5, en declaraciones a los medios de comunicación, el ministro de Sanidad, Servicios Sociales e Igualdad, anunció la intención del Gobierno de realizar reformas para permitir el acceso de los extranjeros en situación irregular a la atención primaria del SNS sin reconocerles la condición de asegurados. ${ }^{\text {II }}$

${ }^{10}$ Las urgencias hospitalarias en el Sistema Nacional de Salud: derechos y garantías de los pacientes. Estudio conjunto de los Defensores del Pueblo, Madrid, enero de 2015, págs. 44-49, https://www.defensordelpueblo.es/informe-monografico/las-urgencias-hospitalarias-en-el-sistema-nacional-de-saludderechos-y-garantias-de-los-pacientes-estudio-conjunto-de-los-defensores-del-pueblo-enero-2015/ (último acceso 0510-2015); Informe anual 2014 y debates en las Cortes Generales, Defensor del Pueblo, Madrid, 2015 https://www.defensordelpueblo.es/informe-anual/informe-anual-2014/ (último acceso 05-10-2015), págs. 297 y ss. También Red de Denuncia y Resistencia al RDL 16/2012 (REDER), Informe: Radiografía... ob. cit.

11 http://politica.elpais.com/politica/2015/03/31/actualidad/1427788718_943883.html (último acceso 05-102015), http://www.elmundo.es/salud/2015/03/31/551a50f522601d677c8b4574.html (último acceso 05-10-2015). 
Tras las elecciones de mayo de 20I5, varias CCAA dictaron normas o instrucciones internas extendiendo el acceso a la atención primaria a los extranjeros en situación irregular. ${ }^{\mathrm{I} 2}$

Entre mayo y septiembre, las CCAA en las que los extranjeros en situación irregular no tenían acceso a la atención primaria han procedido a extender, con determinados requisitos, la atención a este colectivo; o bien se han comprometido a hacerlo en un futuro cercano, con la única excepción de La Rioja.

El panorama, a día de hoy, dista de ser claro. No existe una regulación común para todas las CCAA, ni directrices de coordinación. El día 2 de septiembre se convocó a las CCAA en la Comisión de Prestaciones del Consejo Interterritorial de Salud. En dicha reunión se propuso un documento de mínimos a las CCAA, al que las mismas debían formular sugerencias en I5 días. En octubre de 2015, no hemos podido tener acceso al documento, ni se ha publicado aún ningún acuerdo en este sentido. ${ }^{\mathrm{I} 3}$

En cualquier caso, a la vista de las informaciones del Ministerio y de las medidas autonómicas adoptadas hasta el momento, no parece que vaya a extenderse nuevamente el acceso a la atención sanitaria a los extranjeros irregulares en condiciones de igualdad. La clave parece estar en el no reconocimiento de la condición de asegurado a este colectivo, en la acreditación de la insuficiencia de recursos, y en la exigencia de un periodo mínimo de empadronamiento.

Será necesario esperar el desarrollo de los acontecimientos para poder analizar con claridad el estado de la cuestión.

\section{Algunas preguntas sobre la adecuación constitucional de la medida}

A la vista de las posturas adoptadas por la doctrina científica, encontramos opiniones diversas.

Algunos autores han argumentado que la medida no vulnera la CE, en base a diferentes argumentos extraídos de la jurisprudencia constitucional. ${ }^{4} 4$ Otros, por el contrario, señalan posibles problemas inconstitucionalidad. ${ }^{\mathrm{I} 5}$

\footnotetext{
12 En Valencia, se dicta el Decreto Ley 3/2015, de 24 de julio, del Consell, por el que se que regula el acceso universal a la atención sanitaria en la Comunitat Valenciana (Diari Oficial de la Comunitat Valenciana núm. 7581/29-07-2015). En Aragón, el Departamento de Sanidad del Gobierno de Aragón dicta la Instrucción de 7 de agosto de 2015, del consejero de sanidad, por la que se regula el acceso a la asistencia sanitaria en Aragón para las personas extranjeras sin recursos económicos suficientes ni cobertura de asistencia sanitaria del Sistema Nacional de Salud. En Cataluña, el servicio de salud adoptó la Instrucció 08/2015, Accés a l"assistència sanitària de cobertura pública del CatSalutals ciutadans estrangers empadronats a Catalunya que no tenen la condició d"assegurats o beneficiaris del Sistema Nacional de Salut. En la Comunidad Autónoma de Madrid, la Dirección General de Coordinación de la Asistencia Sanitaria del Servicio Madrileño de Salud ha enviado distintas instrucciones internas en materia de atención primaria y financiación de medicamentos a personas extranjeras en situación irregular con insuficiencia económica.

$13 \mathrm{http}: / /$ www.msssi.gob.es/gabinete/notasPrensa.do?id=3748 (último acceso 05-10-2015).

14 Delgado Del Rincón, «Globalización y extranjería. A propósito de la integración social de los inmigrantes a través de los derechos de acceso a la educación y a la sanidad», en REVIRIEGO PICÓN (coord.) Constitución y globalización. Transformaciones del Estado constitucional, FMGA, Zaragoza, 2013, págs. 238-240. Si bien hay que tener en cuenta que esta opinión parece sensiblemente matizada por el mismo autor en un trabajo posterior, hasta parecer defender la postura opuesta. DELGADo DEL RinCón, «El derecho a la asistencia sanitaria de los inmigrantes irregulares: reflexiones sobre la reforma introducida por el Real Decreto-ley 16/2012, de 20 de abril», REDP, núm 163,2014 , págs. 210 y ss.
} 
Se encuentra extendida la opinión según la cual la medida debe ser sometida, para determinar su legitimidad o ilegitimidad constitucional, a formas de análisis usualmente utilizadas en el enjuiciamiento de normas que inciden sobre derechos fundamentales, como el escrutinio de proporcionalidad o el respeto del contenido esencial. De acuerdo con la opinión de muchos de estos autores, la medida no superaría dicho test. ${ }^{\mathrm{I}} 6$

La cuestión es que, al tratarse de derechos en estrecha conexión con los principios rectores del Capítulo III, dicha técnica puede resultar problemática o inadecuada. ${ }^{77}$ Por ello resulta procedente estudiar en qué medida, y con qué fundamento, pueden ser utilizadas tales técnicas de análisis de constitucionalidad en este caso.

La pregunta acerca de la legitimidad constitucional de la medida desde un punto de vista «material» plantea diferentes cuestiones. Es necesario identificar qué preceptos constitucionales y qué derechos fundamentales podrían, en su caso, verse afectados; así como los distintos condicionamientos que, respecto del legislador, pueden derivar de dichas normas constitucionales. Además hay que tener en cuenta la específica situación constitucional de los no nacionales, para dilucidar si, y hasta qué punto, la condición de extranjero en situación irregular puede llevar asociada una diferencia de trato como la que nos ocupa.

Uno de los preceptos constitucionales que podrían verse comprometidos es el art. 43 CE. Dicho enunciado normativo establece que: «I. Se reconoce el derecho a la protección de la salud; 2. Compete a los poderes públicos organizar y tutelar la salud pública a través de medidas preventivas y de las prestaciones y servicios necesarios. La ley establecerá los derechos y deberes de todos al respecto; 3. Los poderes públicos fomentarán la educación sanitaria, la educación física y el deporte. Asimismo facilitarán la adecuada utilización del ocio».

Este artículo se encuentra dentro del Capítulo III del Título Primero de la CE («De los principios rectores de la política social y económica»). Según la posición mayoritaria en la doctrina científica y constitucional española, de acuerdo con lo establecido en el art. 53 $\mathrm{CE}$, los contenidos presentes en el Capítulo III no se configuran en nuestra constitución como derechos fundamentales en sentido jurídico. ${ }^{\mathrm{I} 8}$

15 AguAdo I Cudolà y PRAdo PÉREZ, «Derecho a la protección de la salud y exclusión de la asistencia sanitaria: la crisis económica como pretexto para la limitación del acceso a los servicios y prestaciones del estado del bienestar», RVAP, núm 99-1000, 2014, págs. 102-104, 109; SOBRINO GUIJARRO, «Inmigrantes irregulares y el derecho a la protección de la salud: análisis de la reforma sanitaria en España», Lex Social-Revista de los Derechos Sociales, núm 1/2012, vol 3, núm 2/2013, 2013, págs. 150 y ss.

16 Aguado I Cudolà y Prado PéRez, «Derecho a la protección...» ob. cit., págs. 102-104; Delgado Del RinCón, «El derecho...» ob. cit., págs. 211 y ss., SOBRINO GUIJARRO, «Inmigrantes irregulares...» ob. cit., págs. 150 y ss.

17 Así, Escobar RocA, «Los derechos fundamentales sociales y la protección de la salud», UNED. Revista de Derecho Político, núm 71-72, 2008, pág. 125, reconoce que no se trata de una cuestión cerrada, aunque aboga por la aplicación de tal esquema «típico de análisis de las intervenciones sobre los derechos de defensa» a los que denomina «derechos fundamentales sociales de prestación», entre los que se encontrarían derechos contenidos en todo el Título Primero.

18 Doctrina bien representada en BASTIDA FREIJEDO, « ¿Son los derechos sociales derechos fundamentales? Por una concepción normativa de la fundamentalidad de los derechos», en Estudios sobre la Constitución española. Homenaje al profesor Jordi Solé Tura, Congreso de los Diputados, Madrid, 2008, págs. 103-149; BASTIDA FrEIJEDO y otros, Teoría general de los derechos fundamentales en la Constitución española, Tecnos, Madrid, 2004. En el mismo sentido, entre otros, Díez-PiCAzo, Sistema de derechos fundamentales, Thomson Civitas, $3^{\text {a }}$ ed., Cizur Menor 
En el constitucionalismo democrático contemporáneo, como consecuencia del carácter normativo y supremo de la constitución, los derechos fundamentales se caracterizan por: I) su indisponibilidad por el legislador; y 2) su potencial disponibilidad inmediata por sus titulares. Sólo son derechos fundamentales aquellos a los que la norma constitucional asigna dichas características. En el caso de la CE, en virtud de lo establecido en el art. 53 CE, serán derechos fundamentales sólo los recogidos en el Capítulo II del Título Primero, y no los establecidos en el Capítulo III del mismo Título u otros preceptos de la CE.

Desde este punto de vista, el artículo 43 CE no contiene derechos fundamentales, porque la constitución encomienda al legislador la configuración jurídica de su contenido, y porque el individuo sólo puede alegarlo en los términos dispuestos en la ley, todo ello de acuerdo al citado artículo 53 CE.

Existen posiciones doctrinales diferentes a este respecto, aunque son posiciones claramente minoritarias. Consideran, con base a diferentes argumentaciones, que del Capítulo III del Título Primero CE -o, según algunas posiciones, de otros preceptos constitucionales- también derivan derechos fundamentales. ${ }^{\text {I9 }}$

Lo anterior no significa que el artículo 43 CE carezca de eficacia jurídica, ni que el derecho a la protección de la salud y el derecho a la asistencia sanitaria no se encuentren protegidos en nuestro sistema constitucional.

En lo que ahora nos interesa, hay que tener en cuenta la intensa vinculación de algunos contenidos del artículo $43 \mathrm{CE}$ con otros preceptos constitucionales que recogen derechos fundamentales, como es el caso del derecho a la vida y el derecho a la integridad física del artículo I5 CE. ${ }^{20}$

El TC se ha referido en repetidas ocasiones a la vinculación entre salud y derechos fundamentales del artículo I5 CE. ${ }^{2 I}$ Resulta especialmente relevante a los efectos de este trabajo que algunas de esas referencias hayan tenido lugar en los dos autos dictados sobre el levantamiento de la suspensión de las normas vasca y navarra que extienden a los

(Navarra), 2008; Rubio LloRENTE, «Derechos fundamentales, derechos humanos y Estado de Derecho», Fundamentos, núm 4, 2006, págs. 203-233; JiMÉNEZ CAMPO, Derechos fundamentales: concepto y garantías, Trotta, Valladolid, 1999; CRUZ VILLALÓN «Formación y evolución de los derechos fundamentales», REDC, núm 25, 1989.

19 Escobar RocA, «Los derechos fundamentales...» ob.cit.; PRIETO SANCHÍs, Estudios sobre derechos fundamentales, Debate, Madrid, 1990. Acerca de las diferentes posiciones doctrinales en España sobre esta cuestión, con una visión a favor de la fundamentalidad de todos los derechos recogidos en el Título I, Gavara DE CARA, Constitución. Desarrollo, rasgos de identidad y valoración en el XXV aniversario (1978-2003), JM Bosch EditorInstituto de Ciencias Políticas y Sociales (ICPS), Barcelona, 2004, págs. 30-32.

20 Delgado Del Rincón, «El derecho a la asistencia sanitaria de los inmigrantes irregulares: reflexiones sobre la reforma introducida por el Real Decreto-ley 16/2012, de 20 de abril», REDP, núm 163, 2014, pág. 207.

21 De acuerdo con la jurisprudencia sentada en SSTC 35/1996/3, 119/2001/6, 5/2002/4, vulneran el artículo 15 $\mathrm{CE}$ los supuestos de riesgo o daño para la salud que generen un peligro grave y cierto para la integridad personal. También se vinculan salud y artículo 15 en las SSTC 48/1996 y 62/2007. Un análisis de esta jurisprudencia en DíAZ CREGO, «El Tribunal Constitucional español y la protección indirecta de los derechos sociales», Lex Social-Revista de los Derechos Sociales, núm 1/2012, 2012, págs. 22 y ss. Acerca de la vinculación entre el art. 43 CE y el derecho a la integridad física, LeÓn Alonso, La protección constitucional de la salud en el marco del Estado Social y Democrático de Derecho, tesis doctoral, Universidad de Salamanca, 2009, págs. 225 y ss., disponible en http:/gredos.usal.es/jspui/bitstream/10366/18595/1/DDPG_Proteccion\%20constitucional\%20salud.pdf (último acceso 05-10-2015). 
extranjeros irregulares el derecho de acceso a la asistencia sanitaria en su respectivo ámbito territorial. $^{22}$

De la jurisprudencia constitucional no puede deducirse un derecho fundamental a determinadas prestaciones sanitarias por parte del poder público. Sin embargo, sí resulta evidente que sus obligaciones respecto de bienes protegidos en el art. I5 CE no son meramente negativas o de respeto.

Surge la duda acerca de si el legislador podría verse condicionado, y cómo, por las obligaciones positivas de protección de los derechos del art. I5 CE a la hora de desarrollar las previsiones del art. 43 CE.

Por otra parte, en esta cuestión -como frecuentemente sucede en relación con los derechos sociales de prestación- entra en juego con mucha fuerza el principio de igualdad. El principio de igualdad jurídica se encuentra recogido en el artículo I4 CE como una de las concreciones normativas del valor superior de la igualdad que impregna la totalidad de la CE. La igualdad jurídica se proyecta sobre los aplicadores del Derecho -igualdad ante la ley$y$, en lo que ahora nos interesa, se configura como límite frente a la actividad normativa de legislador y ejecutivo -principio de igualdad en la ley-. 23

Como es lógico, tal principio no contiene una prohibición absoluta de diferenciación, pues el Derecho opera clasificando y por tanto diferenciando, sino la posibilidad de valorar las diferenciaciones según criterios de racionalidad y no arbitrariedad. Las diferencias introducidas por el legislador deben contar con una fundamentación calificada. Debe existir una relación entre el fin u objeto perseguido y la medida adoptada. Una diferenciación no racional, no justificable, degenera en discriminación.

La aplicación del principio de igualdad y la necesidad de determinar la fundamentación o no de las diferencias ha llevado a diferentes jurisdicciones a acuñar fórmulas que remiten a un juicio de razonabilidad (reasonableness, Angemessenheit, ragionevolezza, razonabilidad), que se relaciona estrechamente con la prohibición de arbitrariedad y el escrutinio de proporcionalidad. Este es el caso de TC español, en cuya jurisprudencia se aprecia la influencia de otros sistemas constitucionales e internacionales. En la formulación jurisprudencial española del escrutinio de razonabilidad como canon de adecuación de las normas legales a la garantía constitucional de la igualdad se encuentra

\footnotetext{
22 AATC 239/2012/5 y 114/2014/8: «Si, además del mandato constitucional, se tiene en cuenta, como ya lo ha hecho este Tribunal, la vinculación entre el principio rector del art. $43 \mathrm{CE}$ y el art. $15 \mathrm{CE}$ que recoge el derecho fundamental a la vida y a la integridad física y moral, en el sentido de lo reconocido por el Tribunal Europeo de Derechos Humanos (por todos asunto VO c. Francia de 8 de julio de 2004), resulta evidente que los intereses generales y públicos, vinculados a la promoción y garantía del derecho a la salud, son intereses asociados a la defensa de bienes constitucionales particularmente sensibles».

23 Respecto del juego del principio constitucional de igualdad jurídica y su relación con las técnicas de escrutinio de la razonabilidad y la proporcionalidad, existe extensa doctrina científica. Zoco, «Dignidad e igual dignidad en la Constitución española», en R. CHUECA (dir.), Dignidad humana y derecho fundamental, CEPC, Madrid, 2015; RocA TRÍAS, Ahumada RuIZ, «Los principios de razonabilidad y proporcionalidad en la jurisprudencia constitucional española», Conferencia «trilateral»Italia/Portugal/España. Reunión de tribunales constitucionales de Italia, $\begin{array}{ccccc}\text { Portugal } y & \text { España, } & \text { Roma, } & \text { octubre } & 2013 .\end{array}$ http://www.tribunalconstitucional.es/es/actividades/Documents/XV\%20Trilateral/PONENCIA.pdf (último acceso 05-10-2015); Gavara De Cara, Contenido y Función del Término de Comparación en la Aplicación del Principio de Igualdad, Aranzadi, Cizur Menor (Navarra), 2005; GiMÉNEZ GlüCK, Juicio de igualdad y Tribunal Constitucional, Bosch, Barcelona, 2004; RUBio LlORENTE, «La igualdad en la jurisprudencia del Tribunal Constitucional. Introducción», REDC, núm 31, 1991, págs. 9-36; JiMÉNEZ CAMPO, «La igualdad jurídica como límite frente al legislador», $R E D C$, núm 9, 1983, págs. 71-114.
} 
presente un componente de proporcionalidad, en lo que se deja ver la influencia del Tribunal Europeo de Derechos Humanos.

Buena parte de la doctrina científica española considera, en esta línea, que la razonabilidad de la diferenciación (y por tanto su adecuación constitucional desde el punto de vista de la igualdad) se determina, entre otros extremos, en función de la adecuación de tal diferenciación a los subcriterios del escrutinio de proporcionalidad.

Por otro lado, aunque la jurisprudencia no siempre es nítida, el TC distingue, en materia de igualdad, entre casos en que se examina el principio de igualdad y casos en que se examina la existencia de discriminación. Ante un posible trato discriminatorio, es necesario utilizar en el juicio de legitimidad constitucional un canon mucho más estricto. Los defensores de la ley deberán probar no ya la razonabilidad de la ley, sino su necesidad para alcanzar un fin constitucionalmente relevante (no simplemente «no contradictorio con la $\mathrm{CE})$.

Realizadas estas consideraciones acerca de los preceptos constitucionales que podrían verse afectados y la relación entre ellos, procede prestar atención a la especial situación de los no nacionales a este respecto.

El art. I3.I CE y la jurisprudencia constitucional asentada en la materia se aplican a todos los derechos y libertades proclamados en el Título I CE (la STC 95/2000/3 se refiere específicamente a la relación entre el art. 43 CE y dicha previsión).

La conocida jurisprudencia constitucional sobre derechos de los extranjeros en España efectúa una clasificación de los derechos del Título I, en función de la mayor o menor discrecionalidad del legislador al regularlos para los extranjeros, identificando: a) derechos de los que los extranjeros deben gozar en plena igualdad de condiciones con los nacionales; b) derechos de los que los extranjeros no pueden gozar, por mandato constitucional; c) toda una gama de situaciones intermedias respecto de las que el legislador tiene un mayor margen de configuración, pero que en todo caso deben respetar determinados condicionamientos (por todas, SSTC I7/2013/2; 236/2007/3 y 4; 99/1985/2; I07/I984/3). ${ }^{24}$ Para determinar la pertenencia a uno u otro grupo, el TC remite entre otros criterios a la vinculación del derecho a la dignidad humana, entendiendo que pertenecientes al primer grupo son los derechos «imprescindibles para la garantía de la dignidad humana». Este criterio de determinación ha sido criticado por una parte de la doctrina científica. 25

La referida jurisprudencia puede suscitar una serie de cuestiones problemáticas, entre las que cabría destacar: dificultades en la determinación del «grupo» a que pertenece

\footnotetext{
${ }^{24}$ Entre los numerosos análisis doctrinales acerca de la jurisprudencia constitucional en la materia y la posición iusfundamental de los extranjeros en España. GOIG MARTíneZ, Multiculturalidad, integración y derechos de los inmigrantes en España, Dykinson, Madrid, 2015; BORRAJO INIESTA, «La posición constitucional de los inmigrantes en Derecho español: el estado de la cuestión en la jurisprudencia», en F.J. Matía PorTilla (coord.), Crisis e inmigración. Reflexiones interdisciplinares sobre la inmigración en España, Tirant Lo Blanch, Valencia, 2012, págs. 253-266; GutiéRREZ, «Volver a las fuentes. Los derechos fundamentales de los extranjeros en la Constitución y en la jurisprudencia constitucional», RGDC, núm 12, 2011; AJA (coord.), Los derechos de los inmigrantes en España, Tirant Lo Blanch, Valencia, 2009; VIDAL Fueyo, Constitución y extranjería: los derechos fundamentales de los extranjeros en España, CEPC, Madrid, 2002.

25 Goig Martínez, Multiculturalidad, integración... ob. cit., págs. 164 y ss., VIDAL FueYo, «Los derechos y libertades fundamentales de los extranjeros en la Constitución española», en E. AJA (coord.), Los derechos... ob. cit., págs. 40 y ss.
} 
cada derecho, dificultades en la individualización de los criterios de adscripción de un derecho a uno $u$ otro grupo, dificultades en la determinación de los condicionamientos que pesan sobre el legislador a la hora de regular los derechos respecto de los que la CE permite un tratamiento desigual. En cualquier caso, una de las cuestiones clave en el problema que nos ocupa es el funcionamiento del principio de igualdad en la legislación que puede incidir en derechos de extranjeros.

El TC ha declarado en reiteradas ocasiones que los derechos fundamentales del art. I5 CE, a la vida y a la integridad física y moral, se encuentran entre aquellos que «corresponden a los extranjeros por propio mandato constitucional y no resulta posible un tratamiento desigual respecto de los españoles» por ser «imprescindibles para la garantía de la dignidad humana» (SSTC 107/1984/3, 236/2007/3).

En cuanto al derecho a la salud, la STC 236/2007 lo coloca entre los derechos respecto de los que el legislador puede establecer «restricciones y limitaciones», que en ningún caso pueden afectar a derechos «imprescindibles para la garantía de la dignidad humana» o al «contenido delimitado para el derecho por la Constitución o los tratados internacionales suscritos por España» (STC 236/2007/4). En este grupo de derechos se colocan algunos derechos vinculados al Capítulo III del Título Primero, como el propio derecho a la salud o el derecho al trabajo (STC 236/2007/4). Plantea cierta perplejidad cuando en el mismo párrafo de la STC 236/2007, se exige, sin diferenciar entre los distintos tipos de derechos referidos con anterioridad (y por tanto aparentemente también respecto de los derechos a la salud o al trabajo), que cualquier condición de ejercicio establecida por el legislador frente a derechos y libertades de los extranjeros en España respete el contenido esencial (con explícita referencia al art. 53.I CE), se dirija a preservar otros derechos, bienes o intereses constitucionalmente protegidos, y guarde adecuada proporcionalidad con la finalidad perseguida (STC 236/2007/4).

En la jurisprudencia constitucional española relativa a la posición constitucional de los no nacionales resulta clave el juego del principio de igualdad y las técnicas de razonabilidad y proporcionalidad. Pese a que el art. I4 CE al proclamar el principio de igualdad se refiere explícitamente a «todos los españoles», el TC ha extendido la aplicación del principio de igualdad a los extranjeros en determinados supuestos, utilizando para ello la precitada clasificación tripartita de los derechos. El juicio de constitucionalidad de los preceptos que afectan a derechos de los extranjeros se configura en ocasiones como un escrutinio acerca de la razonabilidad o proporcionalidad de tales medidas habida cuenta de la condición de extranjeros, o de extranjeros irregulares, de los afectados. ${ }^{26}$

La condición de irregularidad del extranjero, por otra parte, puede ser tenida en cuenta por el legislador, según establece el TC (STC 236/2007), en la configuración legal de sus derechos. Pero los límites citados tampoco dejan de funcionar en este caso.

Por último, resulta básica la referencia al elemento internacional. El art. I0.2 CE configura los tratados internacionales en materia de derechos humanos de los que España sea parte como criterio interpretativo de los derechos fundamentales recogidos en la CE. Además, la jurisprudencia constitucional, teniendo especialmente en cuenta la referencia

\footnotetext{
26 Mora Alemany, «¿También los extranjeros son iguales ante la ley?», Revista de Derecho UNED, núm. 12, 2013, págs. 561-594.
} 
del art. I3.I CE a los tratados internacionales, utiliza dicha normativa internacional como herramienta básica de determinación de las diferencias que puede introducir el legislador entre españoles y extranjeros a la hora de regular sus derechos (STC 236/2007).

No existe un denominador común en materia de derecho a la salud en los diferentes sistemas internacionales de derechos humanos, más allá de la asistencia médica de urgencias y de las obligaciones relativas a los menores de edad. Sin embargo, esta falta de uniformidad no impide identificar la existencia de algunos instrumentos internacionales que amparan el derecho a la asistencia sanitaria integral desde una perspectiva universal, destacando en este sentido el art. I2 PIDESC. 27

Lo expuesto hasta aquí permite sugerir que existe un vínculo jurídico-constitucional entre el art. 43 y el artículo I5 CE. Un vínculo jurídico vivo que está experimentando una transformación asociada a la doctrina jurisprudencial en materia de derechos de los extranjeros, al juego del principio de igualdad y las técnicas jurídicas asociadas de razonabilidad y proporcionalidad y, en fin, a las normas internacionales en materia de derechos humanos.

\section{Los recursos de inconstitucionalidad pendientes ante el TC. Perspectivas abiertas por los AATC 239/20I2 y II4/20I4}

Como se ha mencionado con anterioridad, el RD-ley I6/20I2 se encuentra pendiente de la resolución de varios recursos de inconstitucionalidad. En varios de ellos se cuestiona la legitimidad constitucional del artículo que regula la condición de asegurado, excluyendo de la misma a los extranjeros en situación irregular.

Será necesario esperar a la resolución de los citados recursos para despejar algunas de las dudas planteadas.

No creemos que los cambios políticos y normativos que han venido produciéndose a lo largo de este año, y que suponen que los extranjeros en situación irregular puedan volver a acceder a la atención primaria, disminuyan el interés del pronunciamiento. Por el contrario, sigue siendo crucial la aclaración de los límites a que puede verse sujeto el legislador a la hora de regular el ámbito subjetivo del derecho a la asistencia sanitaria, específicamente cuando entra en juego la posición de extranjeros, más aún de extranjeros en situación irregular.

Es necesario evitar la tentación de considerar, sin más, que los argumentos contenidos en los AATC 239/20I2 y II4/20I4 (que, recordemos, se dictan en un proceso diferente, sobre la constitucionalidad de las normas vasca y navarra que desconocen lo establecido en el RD-ley I6/20I2) suponen una suerte de «adelanto» acerca de cuál puede ser la decisión del TC en los recursos de inconstitucionalidad planteados frente al RD-ley I6/2012.

Estas resoluciones, a pesar su importancia en el tema que nos ocupa, han sido dictadas en el marco de un incidente procesal de levantamiento de la suspensión de una norma autonómica suspendida en virtud del artículo I6I.2 CE.

27 SOBRINO GUIJARRO, «Inmigrantes irregulares...» ob. cit., págs. 137-147. 
En ellas, el TC pondera, de un lado, «el interés general configurado por el beneficio económico asociado al ahorro vinculado a las medidas adoptadas por el Estado al redefinir el ámbito de los beneficiarios del sistema público de salud», y de otro «el interés general de preservar el derecho a la salud consagrado en el art. 43 CE», teniendo en cuenta que el derecho a la salud tiene una importante proyección individual y la vinculación entre este derecho y los derechos fundamentales a la vida y a la integridad física (AATC 239/2012/5; II4/20I4/6, 7 y 8). En ambos casos, decide levantar la suspensión, considerando que los perjuicios económicos que se producirían, además de no resultar probados, serían de menor entidad que los posibles daños a la salud pública y a la individual de los afectados por la medida.

Hay que tener muy en cuenta que la ponderación tiene lugar en el marco de un tipo de incidente procesal específico: la decisión se encuentra desvinculada de la resolución que se adopte en su día acerca del tema de fondo, y la ponderación será distinta de otras precisas para decidir acerca de la legitimidad constitucional de la medida. Se trata de dilucidar si los perjuicios alegados por el recurrente tienen la gravedad y consistencia necesarias como para prevalecer sobre la presunción de legitimidad de la regulación recurrida (ATC II4/20I4/4).

Los argumentos del TC, por tanto, no pueden utilizarse sin más para fundamentar una posible inconstitucionalidad del RD-ley I6/20I2. El TC se está pronunciando acerca de una situación de hecho. Afirmar que en esa situación de hecho se pueden producir perjuicios de difícil o imposible reparación para el derecho a la salud de los extranjeros en situación irregular y para la salud pública no equivale a afirmar la inconstitucionalidad del RD-ley.

De igual modo, la ponderación realizada en este tipo de incidente no tiene por qué coincidir con la ponderación realizada a la hora de decidir acerca de la constitucionalidad de la medida.

Sí es cierto que algunos de los argumentos contenidos en estas resoluciones podrían estar presentes en una eventual resolución de inconstitucionalidad. La situación de hecho general que crea la norma a nivel nacional es similar a la analizada a nivel autonómico, y el derecho a la salud, la integridad física y la vida podrían verse igualmente en peligro. De igual manera, las afirmaciones acerca de la fragilidad de la prueba de los argumentos económicos que pretenden justificar la medida podrían ser determinantes

Así, pese a que el marco de ponderación sea muy distinto a la hora de resolver acerca de la legitimidad constitucional de la medida, los argumentos adelantados en los citados autos podrían ser tomados en cuenta en ella.

En cualquier caso, todo aconseja extremar la cautela a la hora de adelantar conclusiones al respecto.

\section{Conclusión}

La exposición de algunas características relevantes de la regulación que trajo consigo la denegación del acceso a la asistencia sanitaria normalizada de los extranjeros en situación irregular, así como algunos puntos concretos en la evolución de la situación creada por esta regulación, resulta útil para centrar la discusión acerca de la legitimidad constitucional de la citada medida. 
Asimismo, es de utilidad para el desarrollo de tal debate la concreción de una serie de preguntas o cuestiones clave en la resolución del asunto.

La cuestión resulta especialmente complicada, al entrar en juego los principios rectores del Capítulo III del Título I de la CE, en relación con derechos fundamentales. Asimismo, la posición constitucional de los extranjeros en situación irregular resulta especialmente controvertida. Ambos temas conectan con la cuestión de la libertad de configuración normativa del legislador democrático y de las determinaciones constitucionales que pesan sobre el mismo: uno de los temas clásicos del constitucionalismo contemporáneo.

Por lo demás, nos encontramos en un contexto que pone de manifiesto nuevos escenarios de derechos fundamentales, al entrar en juego la posición iusfundamental de sujetos no-nacionales.

Asimismo los condicionamientos derivados del derecho de la UE y de otro tipo de compromisos internacionales resultan cruciales en el escenario bosquejado en este trabajo. Por un lado, existen condicionamientos internacionales que imponen la necesidad de respetar los derechos humanos y fundamentales, mientras que otros compromisos internacionales parecen habilitar la actividad normativa susceptible de incidir en dichos derechos. No se trata de una situación específica del problema analizado en esta comunicación, pero éste sí resulta un buen ejemplo de ella.

Se trata este de un tema polémico, susceptible de suscitar debates de oportunidad política. Pero quizá también de provocar una reflexión desde las categorías jurídicas del Derecho constitucional. 